\title{
Histoplasma capsulatum Antigen Measurement
}

National Cancer Institute

\section{Source}

National Cancer Institute. Histoplasma capsulatum Antigen Measurement. NCI

Thesaurus. Code C154816.

The determination of the Histoplasma capsulatum antigen present in a sample. 